Article

\title{
Bio-Guided Isolation of Acetogenins from Annona cherimola Deciduous Leaves: Production of Nanocarriers to Boost the Bioavailability Properties
}

\author{
Maria Teresa Gutiérrez ${ }^{1,+}\left(\mathbb{D}\right.$, Alexandra G. Durán ${ }^{1,+}+\mathbb{C}$, Francisco J. R. Mejías ${ }^{1}{ }^{(0)}$, \\ José M. G. Molinillo ${ }^{1}{ }^{\circledR}$, Diego Megias ${ }^{2}$, Manuel M. Valdivia ${ }^{3}$ and Francisco A. Macías ${ }^{1, *}$ \\ 1 Allelopathy Group, Department of Organic Chemistry, Institute of Biomolecules (INBIO), \\ Campus de Excelencia Internacional (ceiA3), School of Science, University of Cadiz, 11510 Puerto Real, \\ Spain; mariateresa.gutierrezva@alum.uca.es (M.T.G.); alexandra.garcia@uca.es (A.G.D.); \\ javi.rodriguezmejias@uca.es (F.J.R.M.); chema.gonzalez@uca.es (J.M.G.M.) \\ 2 Confocal Microscopy Unit, Spanish National Cancer Research Center (CNIO), E-28029 Madrid, Spain; \\ dmegias@cnio.es \\ 3 Department of Biomedicine, Biotechnology and Public Health, School of Science, \\ Institute of Biomolecules (INBIO), University of Cadiz, 11510 Puerto Real, Spain; manuel.valdivia@uca.es \\ * Correspondence: famacias@gm.uca.es; Tel.: +34-956-012770 \\ + These authors contributed equally to this work.
}

Academic Editors: Luisella Verotta and Emerson F. Queiroz

Received: 27 August 2020; Accepted: 20 October 2020; Published: 21 October 2020

\begin{abstract}
Annonaceous acetogenins (ACGs) are lipophilic polyketides isolated exclusively from Annonaceae. They are considered to be amongst the most potent antitumor compounds. Nevertheless, their applications are limited by their poor solubility. The isolation of ACGs from Annona cherimola leaves, an agricultural waste, has not been reported to date. Molvizarin (1) cherimolin-1 (2), motrilin (3), annonacin (4) and annonisin (5) are isolated for the first time from A. cherimola deciduous leaves. Annonacin was found to be four- and two-times more potent in tumoral cells (HeLa, 23.6\% live cells; IGROV-1, 40.8\% live cells for $24 \mathrm{~h})$ than in HEK-293 at $50 \mu \mathrm{M}(24 \mathrm{~h}, 87.2 \%$ live cells). Supramolecular polymer micelles (SMPMs) were synthesized to encapsulate the major ACG isolated, annonacin, in order to improve its solubility in aqueous media. The bioavailability of this compound was increased by a factor of 13 in a simulated human digestive system when compared with free annonacin and an encapsulation efficiency of $35 \%$ was achieved. In addition, the cytotoxic activity of SMPMs that hosted annonacin ( $100 \mu \mathrm{M}, 24 \mathrm{~h}, 5.8 \%$ live cells) was increased compared with free annonacin in water $(100 \mu \mathrm{M}, 24 \mathrm{~h}, 92 \%$ live cells). These results highlight the use of by-products of A. cherimola, and their pure compounds, as a promising source of anticancer agents. The use of SMPMs as nanocarriers of ACGs could be an alternative for their application in food field as nutraceutical to enhance the administration and efficacy.
\end{abstract}

Keywords: Annona cherimola; acetogenins; by-products; encapsulation; cytotoxic activity; nutraceutical

\section{Introduction}

Annonaceous acetogenins (ACGs) are fatty-acid derived natural products found only in species of the Annonaceae family [1]. The main economic interest in this family is focused on the edible fruits of some species, which have attractive organoleptic characteristics. More than 400 ACGs-obtained mainly from roots, stems, seeds and, less often, from leaves [2] — have been described in the last few decades. These compounds contain a long aliphatic fatty acid chain with 35-37 carbon atoms, derived from the polyketide pathway [3], a terminal methyl-substituted $\alpha, \beta$-unsaturated $\gamma$-lactone ring and either none, one, two or three tetrahydrofuran (THF) rings that can be adjacent or not adjacent to 
one another [4]. Furthermore, several hydroxyl groups are present in different positions, frequently alongside the THF rings. Overall, the molecular structure comprises two functional moieties: the polar core and the terminal lactone. The biological activity is influenced by the number and stereochemistry of the THF rings and the number of carbon atoms between the polar core and the $\gamma$-unsaturated lactone [5]. For instance, it is considered optimum for activity to have at least 13 carbons in the spacer [6].

Spain is one of the major Annona cherimola Mill. producers worldwide and the fruit, cherimoya, has become an important crop due to its sensorial and nutritional properties [7]. This species is native to Peru and Ecuador and different parts of this plant have been used in folk medicine for centuries, mainly for the treatment of intestinal and skin diseases [8]. For example, leaves preparations have been used to treat digestive and respiratory disorders and the fruit has been employed for the treatment of stomach-ache and pancreatic ulcers [9]. Other applications of acetogenins in food field are the employment of the cherimoya fruit pulp and avocado seed extract as preservative, due to their antioxidant capacity [10,11]. At least 20 ACGs from this species have been isolated from seeds, stems and roots [2]. However, the isolation of ACGs from A. cherimola leaves has not been described to date [12]. These exclusively natural compounds from the Annonaceae family have attracted considerable attention in recent years due to the broad range of biological activities described and the characteristic structures. Cytotoxic, pesticidal, antimicrobial and antimalarial activities, amongst others, have been reported [13]. ACGs are currently considered to be amongst the most potent antitumor compounds. The inhibition of complex I (NADH-ubiquinone oxidoreductase) of mitochondrial electron transport systems [14-16], inhibition of glucose uptake (they are potent modulators of glucose transporters) [17] and a target of the hypoxia-inducible factor-1 (HIF-1) have been well established as modes of action [18]. Furthermore, the effectiveness of ACGs against multidrug-resistant human mammary adenocarcinoma and lung cancer cell lines has been described, with better results obtained than for conventional treatments [5,19]. In spite of these advantages, this kind of compound has very low water solubility and their use in clinical or dietary supplement applications is therefore limited. In some in vivo experiments, ethanolic solutions have been used as a vehicle and, in other cases, in order to improve this vehicle ACGs have been dispersed in $\mathrm{NaCl}$ solution prior to injection [20-24]. The use of organic solvent does not seem to be a good approach for real applications in human studies. Furthermore, the addition of salt could lead to acid-base modification of functional groups of ACGs, such as hydroxyl groups, which would potentially have an impact on side reactions of the bioactive molecule. In this case, the real activity of the original biomolecule would not be observed but those of a different product would [25]. In order to avoid these undesired effects, nanotechnology has increasingly attracted significant attention to enhance the oral administration or food stability [26]. Nanoparticles have emerged as useful tools in medicinal chemistry for real applications, as in case of $\beta$-carotene or curcumin, with remarkable results obtained against melanoma cancer cells [27,28].

The work described here concerns the bio-guided isolation of ACGs from Annona cherimola Mill. deciduous leaves. The investigation of the potential of this by-product could lead to less waste, potential health benefits and an increase industrial profitability. In vitro experiments on different tumoral (human ovarian (IGROV-1) and cervix carcinoma (HeLa) cell lines) and non-tumoral (human embryonic kidney 293 (HEK-293)) cells were performed to evaluate the cytotoxicity of extracts and pure compounds. A supramolecular polymer micelle was synthesized to encapsulate the main ACG isolated from $A$. cherimola leaves, namely annonacin, in an effort to improve the drug-release system [29]. Bioavailability in a simulated gastrointestinal model, stability and solubility were also investigated.

\section{Results and Discussion}

\subsection{Bio-Guided Isolation}

The isolation of ACGs from Annona cherimola leaves has not been reported to date. It is worth highlighting the use of this by-product (deciduous leaves) as a source of bioactive ACGs. Although 
the study and purification of this kind of compounds can require multiple separation techniques [2], five ACGs were obtained in this study by bioassay-guided fractionation (Figure 1 and Figure S1).

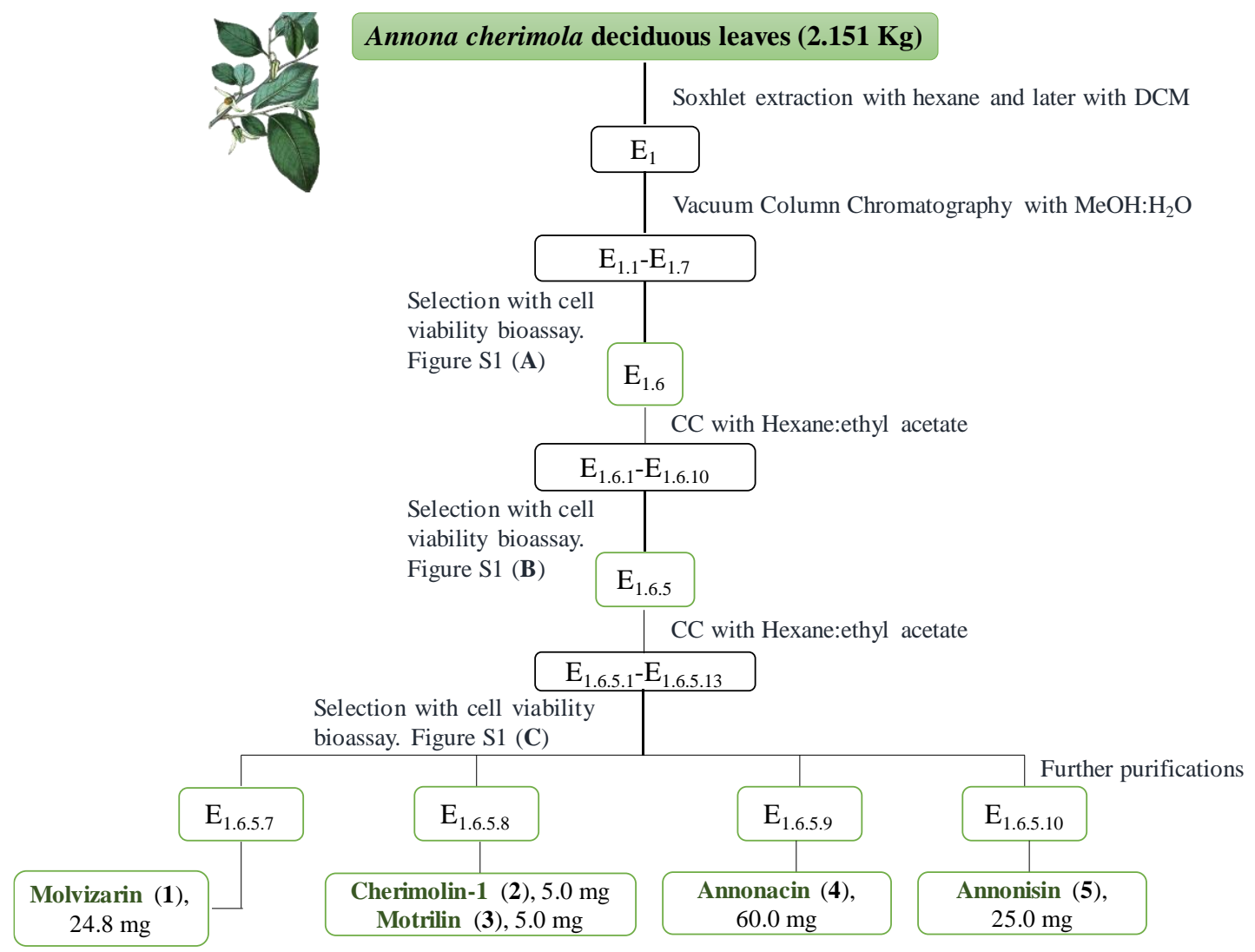

Figure 1. Bio-guided fractionation of $A$. cherimola deciduous leaves. For Figures S1A-C please see supporting information.
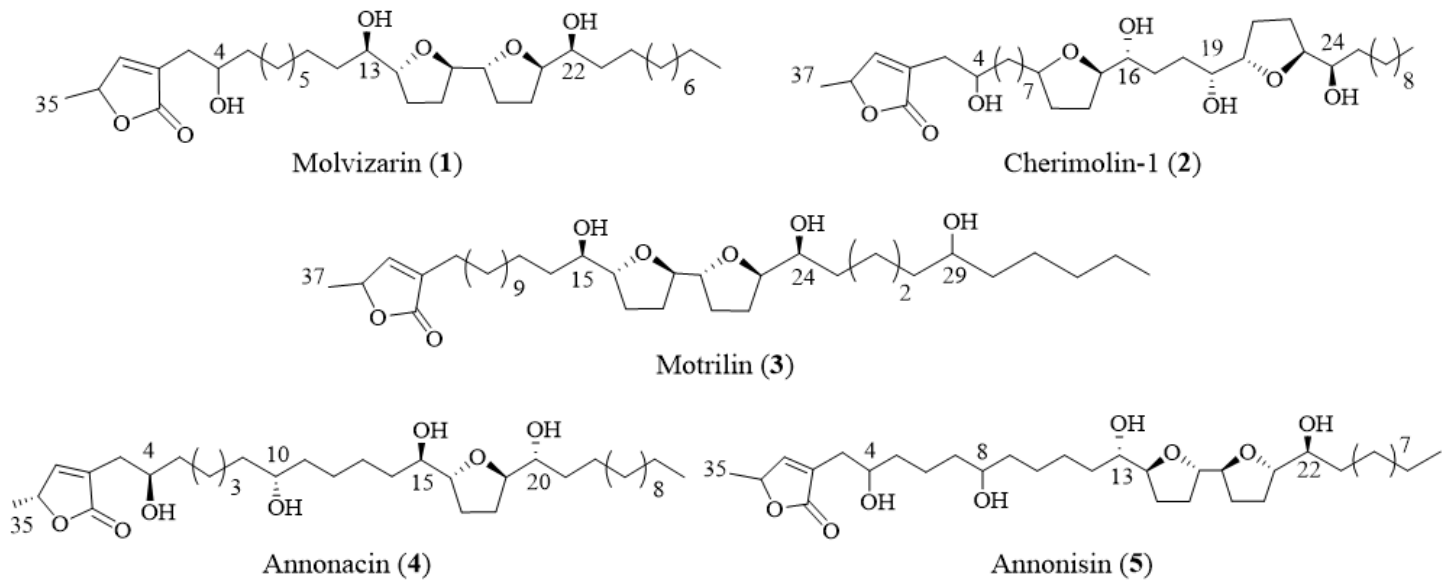

Figure 2. Annonaceous acetogenins (ACGs) isolated from Annona cherimola deciduous leaves.

The structures were elucidated based on HRMS and NMR experiments. The spectroscopic data are consistent with those described previously for: three adjacent bis-THF (molvizarin (1) $(24.8 \mathrm{mg}$, $0.001 \%)$, motrilin (3) (5 mg, 0.0002\%), and annonisin (5) ( $25 \mathrm{mg}, 0.001 \%)$ ), one mono-THF (annonacin (4) $(60.0 \mathrm{mg}, 0.003 \%))$ and one non-adjacent bis-THF acetogenin (cherimolin-1 (2) $(5 \mathrm{mg}, 0.0002 \%))$ (Figure 2) [30-33]. For physical data see supporting information (Supplementary Materials Pages S3-S8). These compounds are described for the first time in Annona cherimola Mill. deciduous leaves and one 
of them (annonisin) has never been isolated from this species before. Yields obtained were similar or even higher to those reported for this family of compounds isolated from Annonaceae [34-36].

\subsection{Cytotoxic Activities of Isolated ACGs}

Isolated ACGs were evaluated against IGROV-1 and HeLa tumoral cell lines at $100 \mu \mathrm{M}$ for $24 \mathrm{~h}$. (Figure 3). Significant cytotoxic activities were observed for all of the ACGs tested. The highest activity values were obtained for compounds 2 and 4 , which gave cell viability values of less than $10 \%$ and were more active than positive control (etoposide). Lower activity was observed when cells were treated with ACG 1, which was approximately seven- and four-times less active than ACGs $\mathbf{2}$ and $\mathbf{4}$ for the Hela and IGROV-1 cell lines. In several studies it has been demonstrated that structural features, such as the number of hydroxyl groups on the aliphatic chain and the spacer between the THF and lactone ring, are crucial factors that influence the activity [37]. In this particular case, it can be suggested that non-adjacent bis-THF (2) and mono-THF (4) ACGs showed better inhibition than adjacent bis-THF ACGs (1, $\mathbf{3}$ and 5). Moreover, the isolated ACGs were slightly more potent against IGROV-1 cells at $100 \mu \mathrm{M}$ for $24 \mathrm{~h}$.

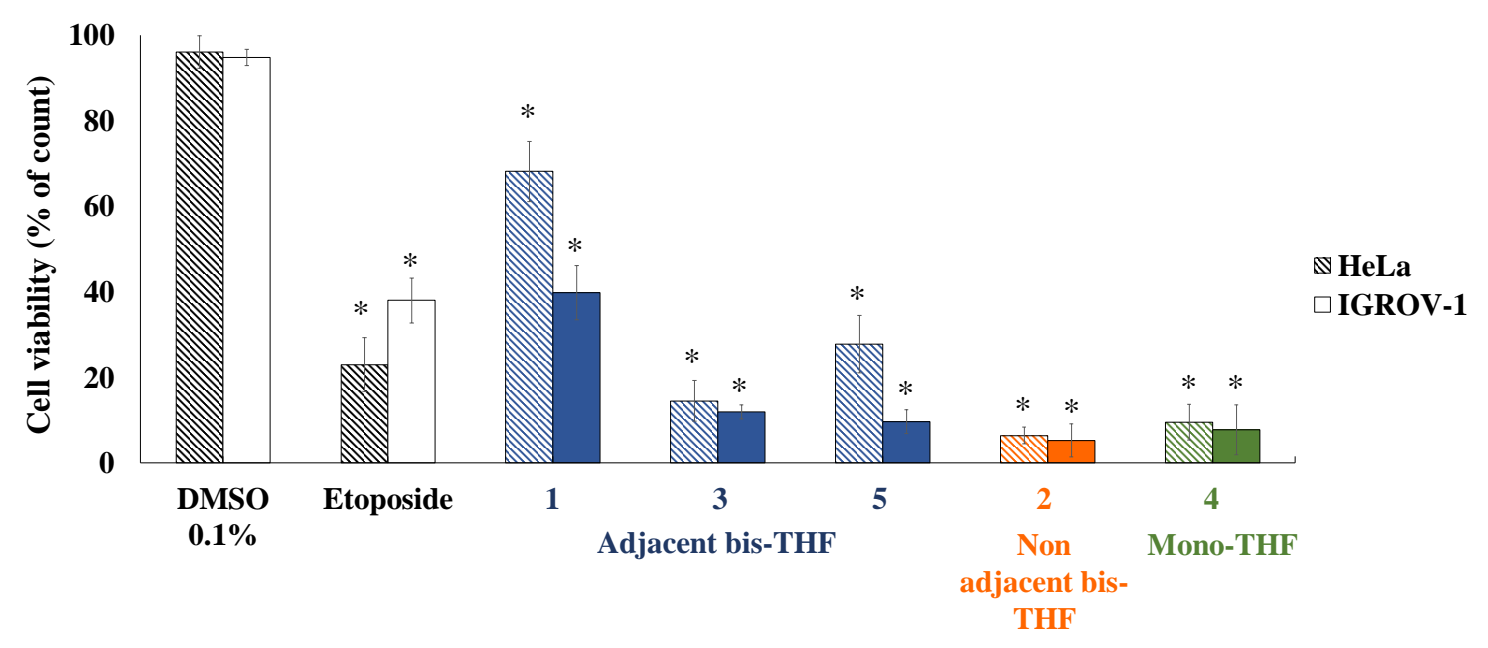

Figure 3. Cell viability by dye exclusion against ovarian (IGROV-1) and cervix carcinoma (HeLa) cells. ACGs 1-5, classified by skeleton using different colors, and positive control (etoposide) were evaluated at $100 \mu \mathrm{M}$ for $24 \mathrm{~h}$. Experiments were performed in triplicate and data are expressed as mean $\pm \mathrm{SD}$, $n=3,{ }^{*} p<0.05$ vs. untreated cells (DMSO $0.1 \%$ ).

In view of the results outlined above, one of the most active ACGs that was also isolated in higher amounts, namely annonacin (4), was selected to perform a cytotoxicity study at various concentrations (from 6.25 to $100 \mu \mathrm{M}$ ) in different tumoral (IGROV-1 and HeLa) and non-tumoral (HEK-293) cell lines (Figure 4 ) for $24 \mathrm{~h}$. It is worth nothing that compound 4 showed selectivity as it proved to be approximately four- and two-times more potent in tumoral cells (HeLa and IGROV-1 respectively) than in non-tumoral human embryonic kidney cells (HEK-293) at $50 \mu \mathrm{M}$. This variation in cytotoxicity is a useful property in the search for potential anticancer compounds. $\mathrm{IC}_{50}$ values of $19.32\left(\mathrm{R}^{2}=0.9823\right)$, $46.54\left(R^{2}=0.9791\right)$ and $68.76 \mu \mathrm{M}\left(\mathrm{R}^{2}=0.9813\right)$ were obtained for HeLa, IGROV-1 and HEK-293 cells, respectively. $\mathrm{IC}_{50}$ values after treatment with annonacin were less than positive control etoposide in tumoral cell lines (HeLa $73.67 \mu \mathrm{M}\left(\mathrm{R}^{2}=0.9942\right)$ and IGROV-1 $\left.59.89 \mu \mathrm{M}\left(\mathrm{R}^{2}=0.9607\right)\right)$. Selectivity index, (SI value expressed as $\mathrm{IC}_{50}$ ratio in HEK-293 cells versus HeLa/IGROV-1 cells) was calculated so as to evaluate the selectivity of annonacin to the cell lines tested. Compounds are classified as high selective if the SI value is $\geq 3$ and less selectivity if it is lower than 3 [38]. Results showed that 4 possess a high degree of cytotoxic selectivity $(\mathrm{SI}=3.55)$ to HeLa cells while it showed less selectivity to IGROV-1 cells $(\mathrm{SI}=2.40)$. 

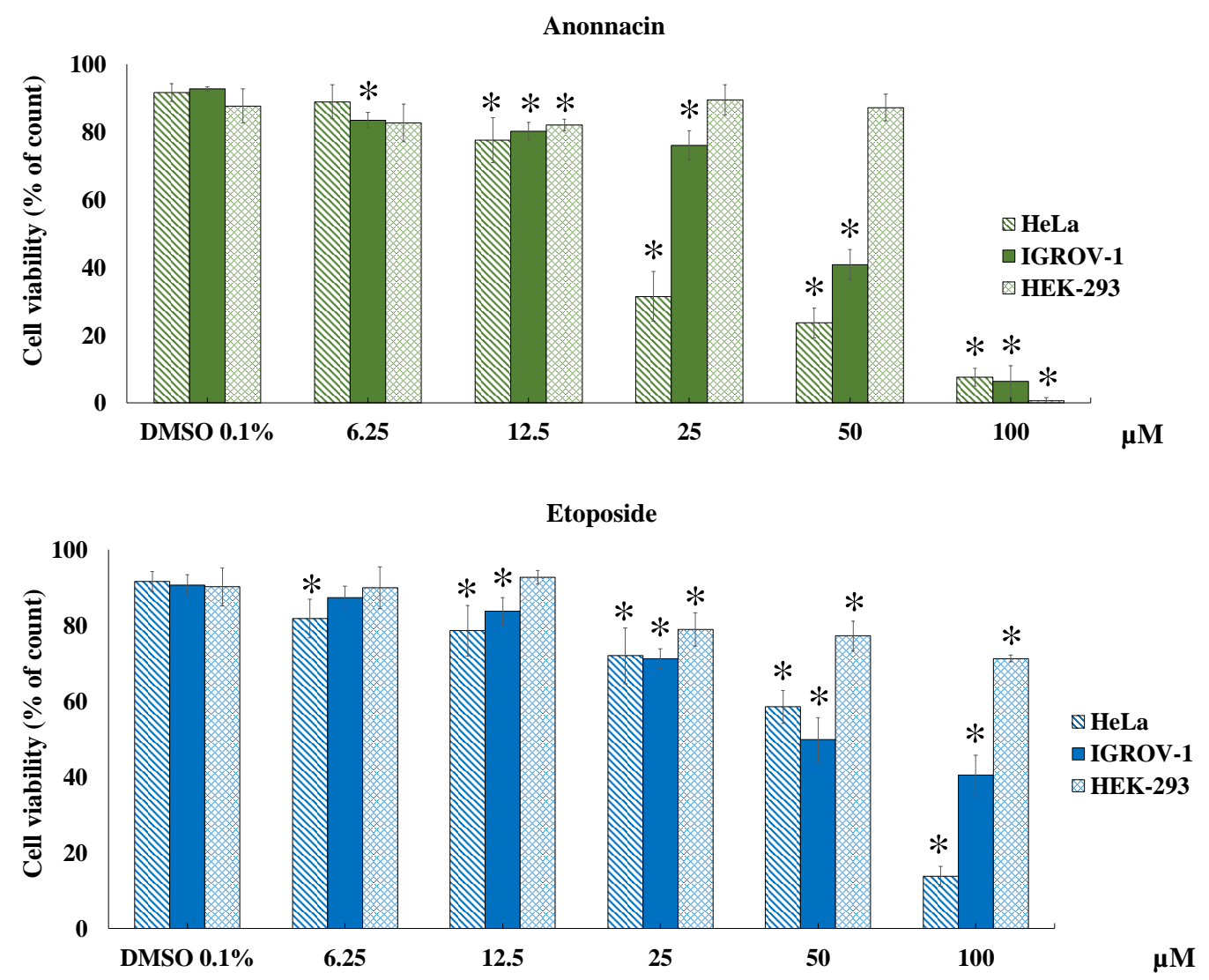

Figure 4. Cell viability by dye exclusion against ovarian (IGROV-1) cervix carcinoma (HeLa) and human embryonic kidney 293 (HEK-293) cells. The ACG and etoposide (positive control) were evaluated at $6.25,12.5,25,50$ and $100 \mu \mathrm{M}$ for $24 \mathrm{~h}$. Experiments were performed in triplicate and data are expressed as mean $\pm \mathrm{SD}, n=3,{ }^{*} p<0.05$ vs. untreated cells (DMSO $0.1 \%$ ).

Caspases play a key role in the apoptotic signaling pathways and caspase- 3 is considered to be the most important of the executioner caspases. After cleavage by caspase-3, DNA fragmentation and a more pronounced and advanced chromatin condensation, or disintegration of the cell into apoptotic bodies take place [39]. To evaluate the mechanisms of annonacin-induced cell death, indirect immunofluorescence caspase-3 study was carried out. Results revealed that the expression intensity of fluorescent caspase-3 on HeLa cells after treatment with annonacin was higher than that in control group (DMSO 0.1\%). These results could confirm that annonacin triggered apoptotic cell death on Hela cells which led to nuclei condensation and fragmentation, as it is indicated in its increase in fluoresce-staining (Figure 5). Our observations in the induction of apoptosis in the cell lines studied corroborate previous studies with ACGs $[40,41]$. It is well documented that the biological activities of ACGs are primarily characterized with toxicity against cancer cells and inhibitory effects against the mitochondrial complex I (mitochondrial NADH: ubiquinone oxidoreductase). That mechanism includes primarily dose-dependent inhibition of complex I of the respiratory chain. Specifically, it has been described that Bis-THF motif of acetogenins binds to the third matrix-side loop of ND1 subunit in mitochondrial NADH-ubiquinone oxidoreductase. The differences observed between the different tumors lines can be explained hypothetically among other reasons by the contribution, in addition to the induction of apoptosis, of additional mechanisms of action such as the influence on glucose transporters and that of hypoxia-inducible factor-1. In this regard, studies have observed that certain ACGs lead to accumulation of intracellular reactive oxygen species (ROS) at the early stage and they may trigger the cell death through a caspase-3 independent pathway. This in turn may explain also the results observed in our case in the use of the non-tumor line HEK-293 where they have been 
different from those of the tumor lines and may contribute in some way to explain the variability of results observed.
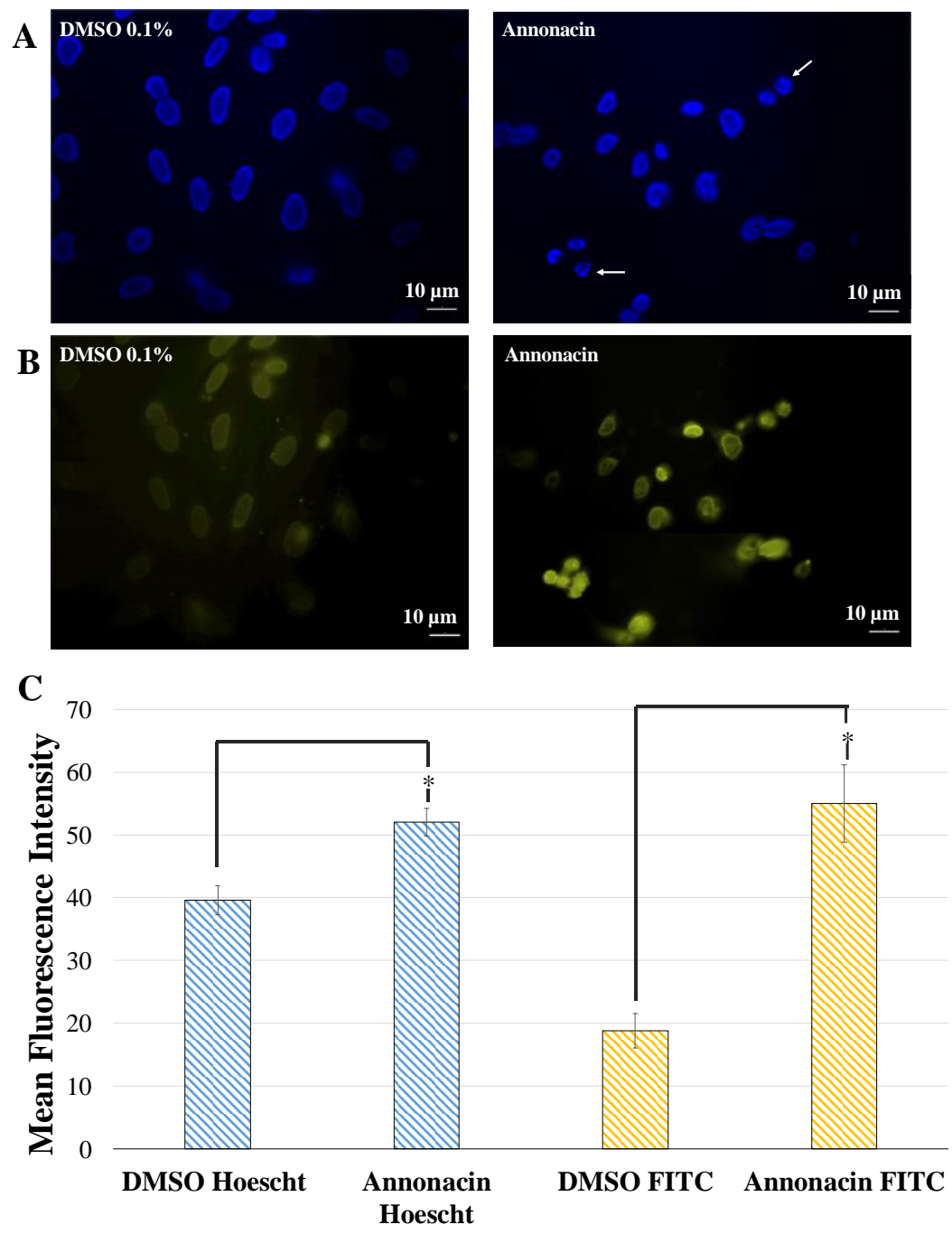

Figure 5. (A) DNA fluorescence staining by Hoechst after treatment with DMSO $0.1 \%$ and annonacin at $100 \mu \mathrm{M}$ respectively for $20 \mathrm{~h}$ on HeLa cells. (B) Secondary anti-rabbit IgG-FITC antibody of HeLa cells treated with DMSO $0.1 \%$ and annonacin at $100 \mu \mathrm{M}$ respectively for $20 \mathrm{~h}$. (C) Quantification of mean fluorescence intensity signal in HeLa cells treated with DMSO 0.1\% and annonacin after indirect immunofluorescence caspase- 3 assay. Data are expressed as mean $\pm \mathrm{SEM}, n=3,{ }^{*} p<0.05$ vs. untreated cells (DMSO 0.1\%).

\subsection{Synthesis of SMPMs of Annonacin}

A supramolecular polymer micelle was synthesized to encapsulate the annonacin. The building blocks of the system were $\alpha$-cyclodextrin and urea (Figure 6). These compounds form the hydrophilic part of a micelle, with the aim of increasing the solubility and bioavailability of annonacin. Intermolecular forces, such as hydrogen bonds, $\pi$ - $\pi$-stacking interactions, electrostatic and van der Waals forces [42,43], established between the polyrotaxane and acetogenins allow the annonacin to be locked within the shell formed by the cyclodextrin with urea inside the toroid structure. Vigorous mixing between the water phase, which contained the cyclodextrin and urea, and the organic phase, which contained the annonacin, led to the 'sequestration' of the acetogenin into the $\alpha-\mathrm{CD} /$ urea inclusion complex. The synthesis procedure required a temperature of $40^{\circ} \mathrm{C}$ or above to favor micelle formation. However, the temperature was kept at $40{ }^{\circ} \mathrm{C}$ to avoid annonacin degradation $\left(<60{ }^{\circ} \mathrm{C}\right)$. 

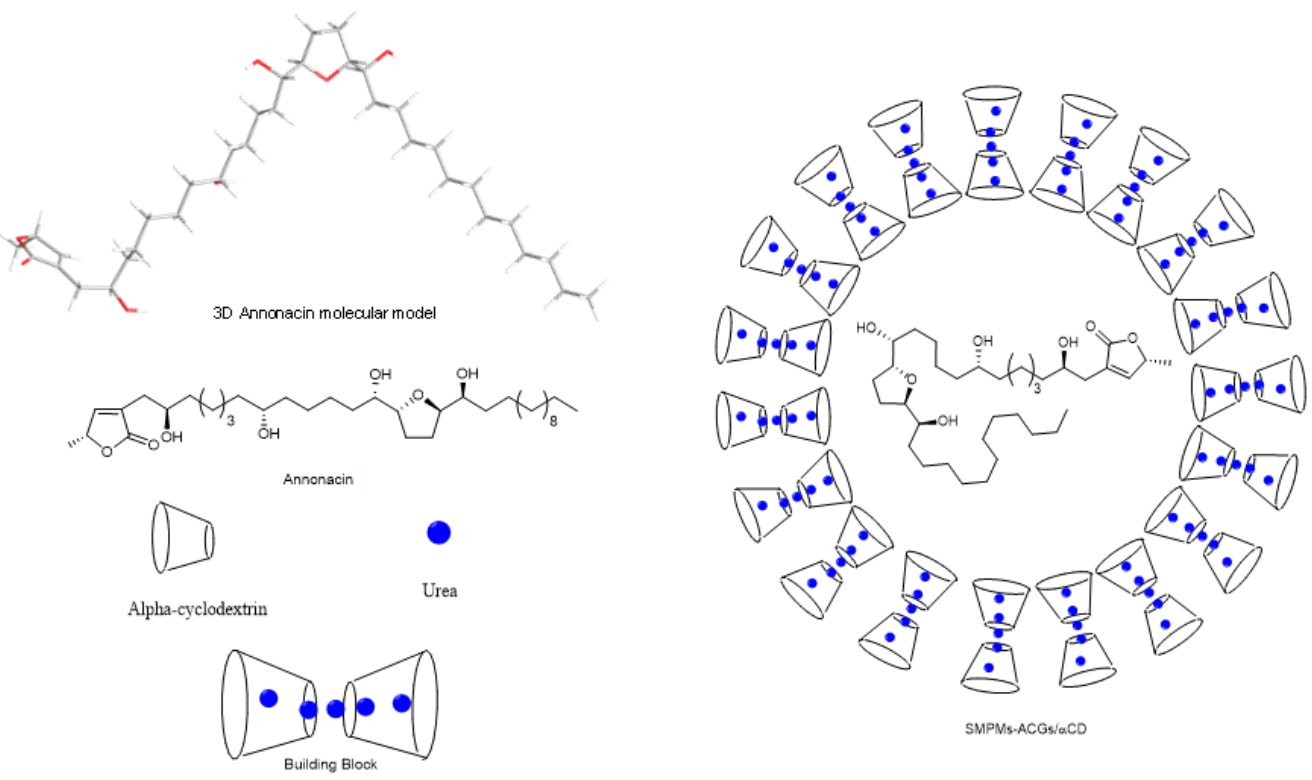

Figure 6. 3D model of annonacin and the formation of supramolecular polymer micelles.

Under the above conditions $~ 35 \%$ ACG encapsulation was achieved, as determined using the UV-Vis calibration curve obtained at $284.9 \mathrm{~nm}$. The structural integrity of annonacin was verified by ${ }^{1} \mathrm{H}-\mathrm{NMR}$ spectroscopy on the supramolecular polymer micelles (SMPMs) after release of the encapsulated acetogenin with $\mathrm{CDCl}_{3}$. Critical micellar concentration was afforded to analyze the correct formation of the micelles. A CMC experiment has been carried out following the method previously described in the literature [44-46]. The SMPMs structures present a non-polar cavity where $\beta$-carotene can be hosted offering a less energetic state. Initially, the carotenoid is fully insoluble in water media, but the formation of the micelle allows to increase the solubility and it will decrease the absorbance due to entrapment inside the micelle. According to this idea, 14 samples with the same amount of $\beta$-carotene ( $1 \mathrm{mg}$ ) were prepared and the concentration of $\alpha$-CD and urea were increased gradually. Figure S8 shows a progressive ascending with the concentration of the encapsulation agents which meet to a co-dissolution of all the compounds. Nevertheless, at $10 \mathrm{mM}$ appears a sharp decrease of the absorbance which point out the formation of the micelles and the input of the $\beta$-carotene.

\subsection{Characterization of SMPMs by NMR Spectroscopy and Electron Microscopy}

The influence of urea encapsulation and SMPM formation could be evaluated by the ${ }^{1} \mathrm{H}-\mathrm{NMR}$ shifts of $\alpha$-cyclodextrin (Figure S2). When urea molecules are hosted by cyclodextrins, the $\mathrm{H}_{1}$ signal is shifted most strongly to low field. Furthermore, the $\mathrm{H}_{4}$ signal is also shifted to low field. These changes suggest that the most relevant interaction between the cyclodextrin and the urea involves the ether oxygen of an $\alpha-1,4$ bond through dipolar interactions. In the case of supramolecular micelle formation, all of the proton signals had modified positions and the resolution decreased. This change is observed because the micelles are not in a true solution-a situation that reduces the solvent interaction and makes the spectra more similar to solid NMR spectra. The authors suggest that the -OH groups are arranged outside the micelles, thus displaying a hydrophilic face, which would imply a change in the most stable conformation (chair) and would explain the marked changes in the shifts of all proton signals. Finally, the micelles are fully broken upon treatment with an organic solvent, such as phenol, and the original signals were restored.

The results of ROESYAD 2D experiments (Figure S3) were not conclusive due to the low resolution of the annonacin signals. The inclusion of annonacin within the SMPMs hinders the elucidation and the system behaves as a quasi-solid NMR sample, as shown by the spectrum of $\alpha$-CD in Figure S2c. Evidence for correlation between signals was not observed for annonacin and cyclodextrin 
in the ROESYAD 2D experiments and this leads to two possible conclusions. Firstly, it is possible that the limitations of the experiment preclude the elucidation of a spatial relationship between shell and core in SMPMs. The second explanation is a possible inter-arrangement of urea units that establishes a 'bridge' of intermolecular forces between the acetogenin and the $\alpha$-CD. In this case, the ${ }^{1} \mathrm{H}$ signals of urea were not observed because of rapid interchange of the amine hydrogen atoms with the solvent.

The morphologies of the SMPMs were studied by transmission electron microscopy. The use of a staining process with heavy elements was avoided because the presence of contaminant compounds or agglomeration could hinder the analyses by microscopy. The images (Figure 7) are consistent with the structure proposed in Figure 6, where the polyrotaxanes composed of $\alpha$-CD with encapsulated urea form the hydrophilic phase of the micelles. The morphologies are predominantly spherical with a wall thickness of $8 \pm 1 \mathrm{~nm}$ (Figure S4). There seem to be two main groups of SMPMs present, one with sizes between 100 and $160 \mathrm{~nm}$ in diameter and the other with diameters between 80 and $30 \mathrm{~nm}$ (Figure S5). It is worth mentioning that despite the large sizes of these particles they are still within the nanomedicine application range to overcome the barriers of liver and spleen, according to Cabral and co-workers [47]. According to the literature [48], the shell sizes are around $6 \mathrm{~nm}$ and it was concluded that this is consistent with two $\alpha$-CD units linked by secondary intermolecular forces with several units of urea. Nevertheless, two semi-empirical (PM3) simulation studies with two units of the cyclodextrin and thirty two units of urea (1:16 molar ratio) (Figure S6) were carried out. By approximating the model proposed by Dong et al., a truncated cone geometry between two cyclodextrins was found, with urea molecules filling the outer- and inter-spaces where the narrow parts of the cone are closer than the wider parts. This simulation gave a shell thickness of $\sim 18 \AA$. Given the significant difference compared to the thickness values reported in the literature, a biased geometry between cyclodextrins was assessed. In the biased case a minimum conformation energy was obtained for an $\alpha$-CD distance of $\sim 26 \AA$. The authors therefore suggest that between six and eight $\alpha$-cyclodextrin molecules connected with urea units constitute the membranes in this specific SMPM with annonacin. The limitations in the theoretical calculation method preclude an explanation for the particular stability of the $8 \mathrm{~mm}$ shell for the encapsulated ACG, which is a common feature of all of the TEM images.
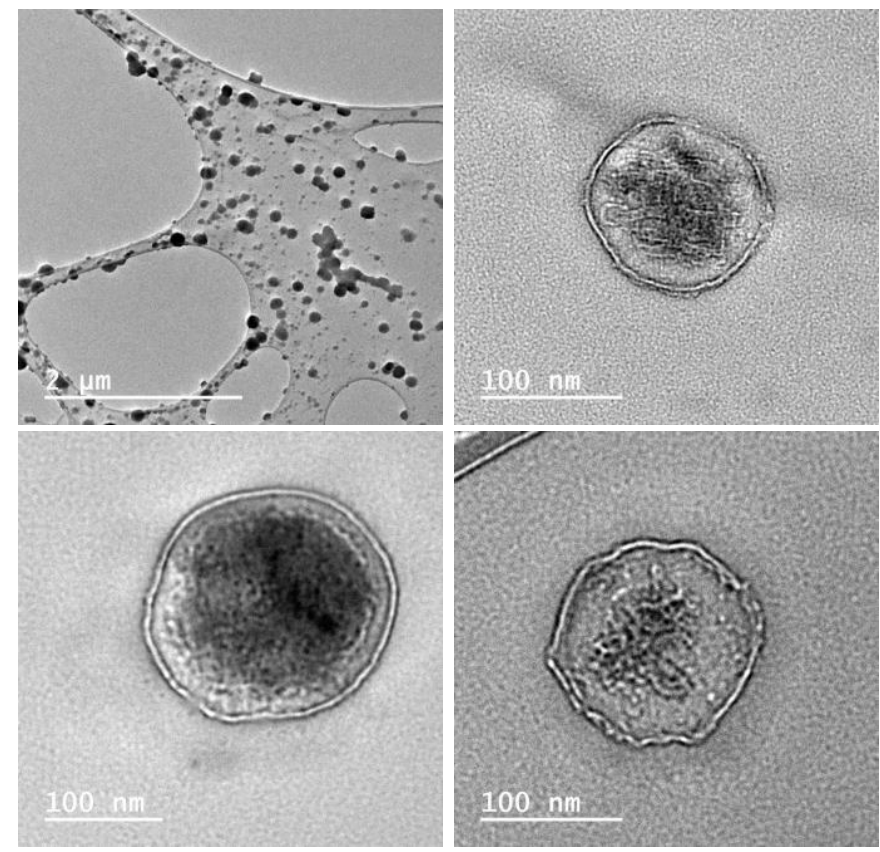

Figure 7. TEM images of supramolecular polymer micelles (SMPMs)-ACGs.

Focusing on the larger SMPMs, the internal volume of the micelle is in the range between $3.10 \times 10^{-4}$ and $1.56 \times 10^{-3} \mu \mathrm{m}^{3}$. The molecular volume of the annonacin was calculated by the semi-empirical 
PM3 method and a molecular volume of $1.715 \times 10^{-9} \mu \mathrm{m}^{3}$ was obtained, which in turn means a range of 0.3-1.514 attomole of annonacin per SMPM in the case where the micelle has a diameter of over $100 \mathrm{~nm}$.
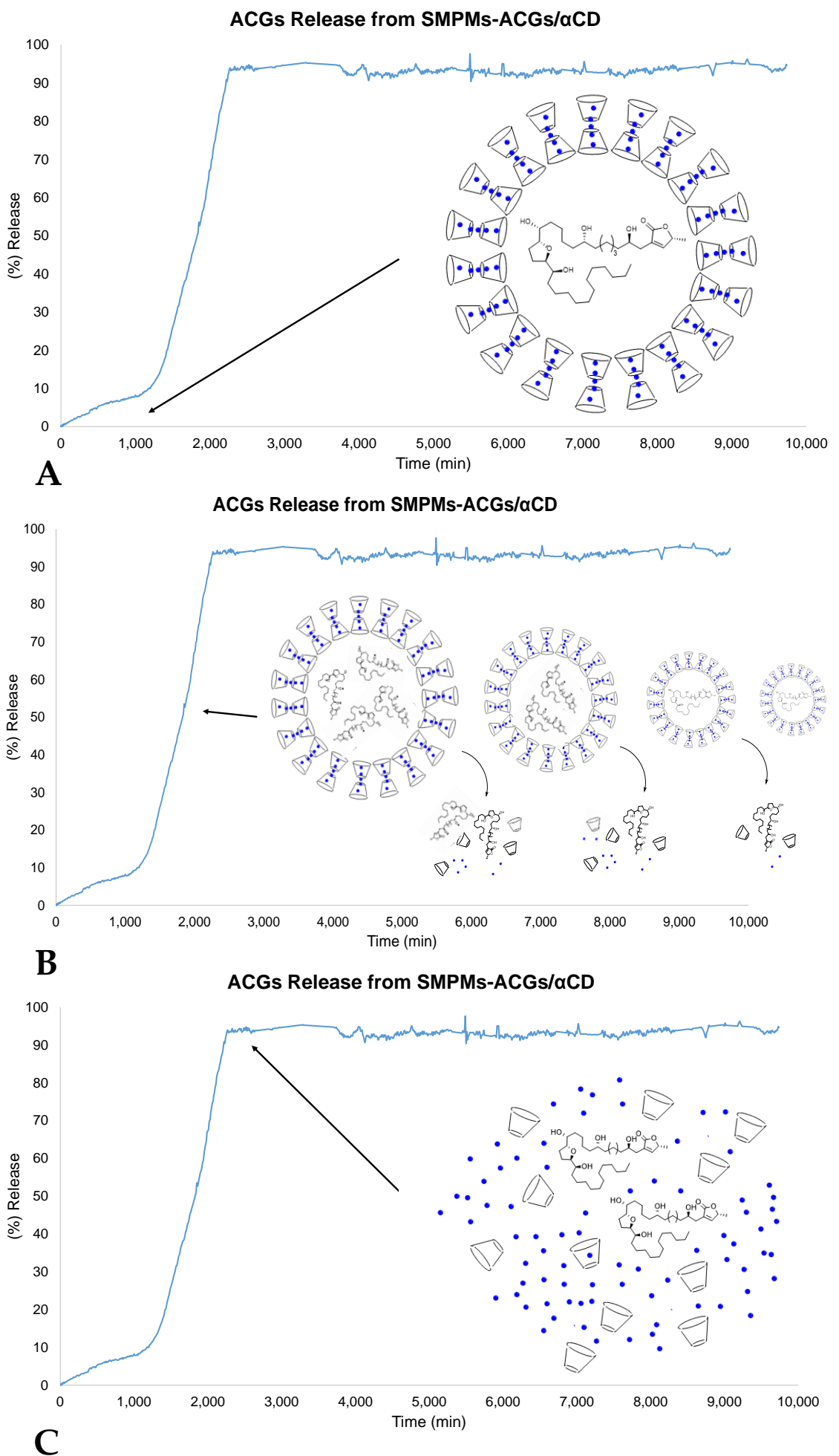

Figure 8. Delivery of annonacin from SMPMs according to UV-Vis studies. (A) Early stages with stable SMPMs. (B) Delivery process according to the Hixson-Crowell model. (C) Stationary state with bioavailable annonacin. 
X-ray diffraction from 3.5 to $75.02 \theta$ degrees were afforded to corroborate that structures observed are micelles and they are not crystallized cyclodextrins, or any crystal derivatives. According to Figure S9, it can be seen that SMPMs are completely amorphous, in comparison with crystallinity showed by $\alpha$-cyclodextrin sample. If the SMPMs-ACGs sample were composed by cyclodextrins crystallites or crystal-like structures, peaks could be observed in X-Ray diffraction experiment, instead of broad signals that are observed in Figure S9B.

\subsection{Controlled Release Study}

Release profile analysis become necessary to understand future in vivo studies. The time required to release completely to solution acetogenins from the SMPMs shell was studied at $37^{\circ} \mathrm{C}$ in saline buffer at $\mathrm{pH}$ 7.4. These experiments provided information on the time period over which annonacin is stable in putative biological media such as blood. As a first approach, the variation in UV-Vis intensity at the characteristic wavelength for annonacin $(284.9 \mathrm{~nm})$ was followed to evaluate the steps involved in the delivery process. In the first $17 \mathrm{~h}, \alpha$-cyclodextrin and urea maintained a stable shell structure, with a time of $33 \mathrm{~h}$ passing until the release process was triggered. The delivery profile shown in Figure 8 indicates that the encapsulated compound is available in PBS solution for at least seven days. However, the behavior in cell media could be slightly different due to the crossing of lipophilic membranes or the action of enzymes.

Different kinetic models were tested to explain the drug release behavior of the annonacin in the medium investigated (Zero order, First order, Higuchi Model, Korsmeyer-Peppas Model, Weibull Model and Hixson-Crowell Model) [49,50]. Two models came close to fitting the behavior of the SMPMs, namely the first order and Hixson-Crowell models, with the latter being the most accurate:

$$
\begin{aligned}
& \mathrm{W}_{\mathrm{t}}^{1 / 3}=\mathrm{W}_{0}^{1 / 3}-\mathrm{k} \cdot \mathrm{t} \quad \mathrm{R}^{2}=0.959 \text { (Hixson-Crowell model) } \\
& \mathrm{Ln}\left(\mathrm{W}_{\mathrm{t}}\right)=\mathrm{Ln}\left(\mathrm{W}_{0}\right)-\mathrm{k} \cdot \mathrm{t} \quad \mathrm{R}^{2}=0.885 \text { (First order model) }
\end{aligned}
$$

The Hixson-Crowell method indicates that SMPMs have a regular area that is proportional to the cube root of their volume. $W_{0}$ is the initial amount of annonacin, $W_{t}$ is the remaining amount of annonacin encapsulated at time $t$, and $\mathrm{k}$ is a constant that reflects the surface/volume relation. The expression represents the release from a system in which there is a change in the surface area and diameter of particles. Equilibrium conditions are not modified and the surface of the SMPMs decreases proportionally over time, in such a way that the initial geometrical remains constant (Figure 8B) [51]. In this model it is assumed that the annonacin release is limited by dissolution velocity and not by diffusion [52]. In this particular case, the experimental data can be expressed as $\mathrm{W}_{\mathrm{t}}^{1 / 3}=-0.2073-0.0016 \cdot \mathrm{t}$.

A comparative study on the bioavailability of free annonacin and encapsulated annonacin showed an improvement by a factor of 13 on using SMPMs with $\alpha-C D$ and urea. The hydrophilic surface provided by the shell part of cyclodextrin and urea allowed the transport and dissolution of the active compound in a simulated oral phase. The majority of the ACGs are then degraded by the strongly acidic medium present in the gastric phase, but the supramolecular structure retains enough protected annonacin to transport it to the intestinal phase. The neutral medium in this latter phase does not seem to damage the micelles, but high concentrations of enzymes, such as lipase, could contribute to the hydrolysis of cyclodextrins. Free annonacin showed a value of $3.68 \%$, but most of the sample could not be solubilized in the initial oral phase due to its low water solubility. Encapsulated annonacin showed a bioavailability of $47.01 \%$, which supports the use of SMPMs in aqueous media over free ACGs.

\subsection{Cytotoxicity Bioassay on SMPMs of Annonacin}

The cytotoxicity of the SMPMs that hosted annonacin against IGROV-1 cells was evaluated at $100 \mu \mathrm{M}$ for $24 \mathrm{~h}$. The highest activity in aqueous media was achieved with encapsulated annonacin (Figure 9) while a solution of free annonacin in water did not show significant activity. Moreover, it is 
worth highlighting that the cell growth inhibition value of SMPMs was very similar to that obtained with free annonacin dissolved in DMSO and both were lower than etoposide.

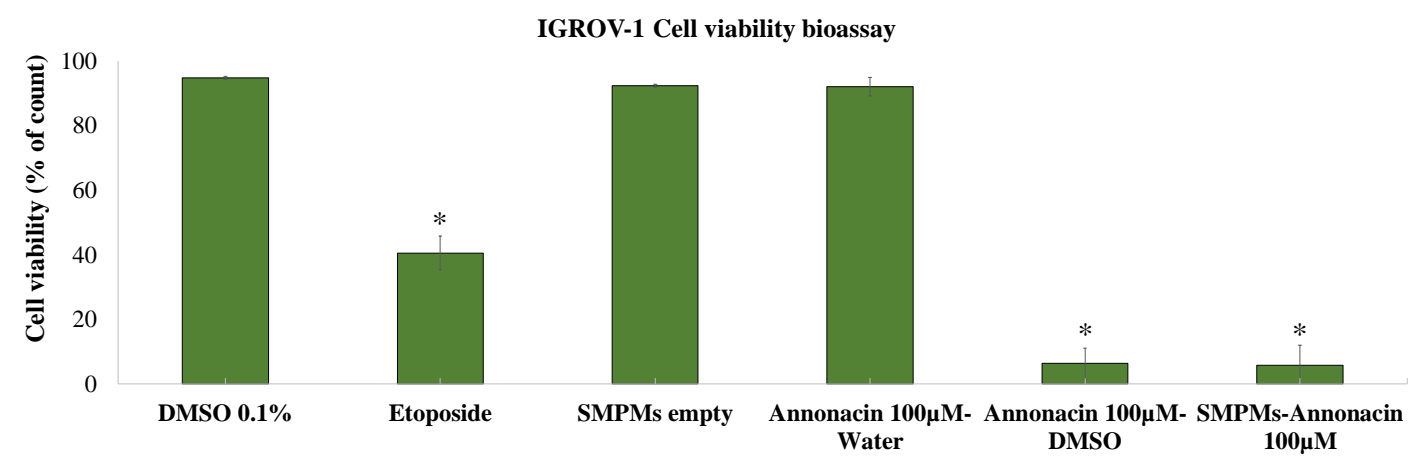

Figure 9. Cell viability by dye exclusion against ovarian carcinoma cells (IGROV-1). Etoposide, SMPMs empty, annonacin and SMPMs hosting annonacin were evaluated at $100 \mu \mathrm{M}$ for $24 \mathrm{~h}$. Experiments were performed in triplicate and data are expressed as mean $\pm \mathrm{SD}, n=3,{ }^{*} p<0.05$ vs. untreated cells (DMSO 0.1\%).

The transport property of the SMPMs has an important advance in direct clinical applications. Avoiding the organic solvent employment, it is decreased possible side effects in a future in vivo treatments. These results reinforce that not only water solubility despite biorecognition has been boosted. Sugar fragments that constitute the SMPMs seems to be relevant in the cell input and this also provide a stable drug transport to the target. Even degradation of the compound could be diminished by SMPMs, because of there is no contact between annonacin and cell media in contrast with application of DMSO (miscible in water) that do not prevent side reactions.

\section{Materials and Methods}

\subsection{General Experimental Procedures}

All of the fractions obtained in the bio-guided isolation and the pure ACGs were characterized by ${ }^{1} \mathrm{H}-\mathrm{NMR}$ and ${ }^{13} \mathrm{C}-\mathrm{NMR}$ spectroscopy. ${ }^{1} \mathrm{H}$ and ${ }^{13} \mathrm{C}$ spectra were recorded at room temperature, using $\mathrm{CDCl}_{3}$ as solvent, on Agilent INOVA spectrometers at 500 and $125 \mathrm{MHz}$ and 600 and $150 \mathrm{MHz}$, respectively. The residual chloroform signal was set to $\delta 7.25 \mathrm{ppm}$ for ${ }^{1} \mathrm{H}$ and to $\delta 77.0 \mathrm{ppm}$ for ${ }^{13} \mathrm{C}$. Furthermore, ${ }^{1} \mathrm{H}-\mathrm{NMR}$ and ROESYAD experiments on the encapsulated compound were carried out at $25{ }^{\circ} \mathrm{C}$ using $\mathrm{D}_{2} \mathrm{O}$ as solvent on an Agilent INOVA spectrometer at $500 \mathrm{MHz}$ and $600 \mathrm{MHz}$. The residual peak for water was referenced to $\delta 4.79 \mathrm{ppm}$. HRMS were obtained on a SYNAPT G2 mass spectrometer (Waters, Milford, MA, USA). HPLC was carried out on an HPLC chromatograph with an RI detector (Merck-Hitachi, Tokyo, Japan) and an analytical column Phenomenex ${ }^{\circledR}$ Luna $10 \mu$ Silica (2) $(250 \times 4.60 \mathrm{~mm}, 10 \mu \mathrm{m})(\mathrm{CA}, \mathrm{USA})$. Silica gel 0.060-0.200, $60 \AA$ from Acros Organics (Geel, Belgium) and Lichroprep RP 18 (40-63 $\mu \mathrm{m})$ from Merck (Darmstadt, Germany) were used for column and vacuum column chromatography. Thin layer chromatography (TLC) was run on Silica gel $60 \mathrm{~F}_{254}$ and Silica gel 60 RP-18 $\mathrm{F}_{254} \mathrm{~S}$ aluminum sheets from Merck (Darmstadt, Germany). For further purification, preparative layer chromatography (PLC) Silica gel $60 \mathrm{~F}_{254} 0.5 \mathrm{~mm}$ was used and this was also supplied by Merck (Darmstadt, Germany).

\subsection{Chemicals}

Ethyl acetate and $n$-hexane were purchased from VWR International (Radnor, PA, USA). Methanol and dichloromethane were obtained from Fisher Scientific (Loughborough, UK) and dimethyl sulfoxide and urea were supplied by Panreac Quimica SAU (Castellar del Vallés, Barcelona, Spain). Deuterated chloroform for spectroscopic experiments was obtained from VWR Chemicals Prolabo ${ }^{\circledR}$ (Leuven, Belgium). For the cytotoxicity bioassays, Dulbecco's Modified Eagle's Medium (DMEM) was supplied 
by Lonza (Verviers, Belgium), premixed phosphate buffer saline solution (PBS, 10 $\times$ ) was supplied by Roche (Steinheim, Germany), fetal bovine serum, penicillin/streptomycin, l-glutamine, sodium pyruvate, trypsin and minimum essential medium non-essential amino acids (MEM NEAA), RPMI 1640 medium were purchased from Gibco (Paisley, UK). $\alpha$-Cyclodextrin $(\alpha-C D)$ was obtained from Tokyo Chemical Industry (TCI Europe, Zwijndrecht, Belgium). Water (type I) was obtained from an Ultramatic system from Wasserlab. Lipase from porcine pancreas (L3126; enzymatic activity of 100-500 units), mucin from porcine stomach type II (M2378), pancreatin from porcine pancreas (P7545; $8 \times$ U.S.P. specifications) and pepsin from porcine stomach mucosa (P7000; enzymatic activity of 500 units/mg solid) were obtained from Sigma Aldrich (Steinheim, Germany).

\subsection{Plant Material}

Leaves from the 'Fino de Jete' variety were collected in October 2014 from an experimental field located in Almuñecar (Spain) ( $\left.36^{\circ} 44^{\prime} 2.1^{\prime \prime} \mathrm{N} 3^{\circ} 41^{\prime} 26.6^{\prime \prime} \mathrm{O}\right)$. Leaves, $(2.2 \mathrm{Kg})$ were dried at room temperature pulverized in an industrial mill and kept at room temperature in absence humidity prior to extraction.

\subsection{Extraction and Isolation}

Dried material $(2.2 \mathrm{Kg})$ was extracted with $4 \mathrm{~L}$ of $n$-hexane using the Soxhlet method $(159 \mathrm{~g}$, $7.4 \%$ yield). Defatted material was extracted with dichloromethane to yield $140 \mathrm{~g}$ after removal of the solvent under reduced pressure $\left(E_{1}\right)$. This residue was further purified by vacuum column chromatography with reverse phase silica gel (RP-18) with different ratios of $\mathrm{MeOH}: \mathrm{H}_{2} \mathrm{O}$ from $100 \%$ water to $100 \%$ methanol with increases of $20 \%$. Seven fractions were obtained $\left(\mathrm{E}_{1.1}-\mathrm{E}_{1.7}\right)$. Fraction $\mathrm{E}_{1.6}$ ( $28 \mathrm{~g}, 1.3 \%$ yield) showed the lowest cell viability and it was therefore subjected to a new separation by silica gel column chromatography using a gradient of hexane:ethyl acetate (from 5 to $100 \%$ ethyl acetate with increases of $10 \%)$ as eluent. In this case, ten fractions $\left(\mathrm{E}_{1.6 .1}-\mathrm{E}_{1.6 \cdot 10}\right)$ were obtained and the most active fraction $\left(E_{1.6 .5}, 2.57 \mathrm{~g}, 0.12 \%\right.$ yield) was selected for further resolution. $E_{1.6 .5}$ was separated by column chromatography on silica gel using a gradient of hexane:ethyl acetate in the same way as described above. Thirteen fractions $\left(\mathrm{E}_{1.6 .5 .1}-\mathrm{E}_{1.6 .5 .14}\right)$ were collected and combined on the basis of similar TLC patterns. The presence of ACGs was confirmed by NMR experiments and fractions $\mathrm{E}_{1.6 .5 .7}-\mathrm{E}_{1.6 .5 .12}$ were confirmed to be active in cell bioassays. Fraction $\mathrm{E}_{1.6 .5 .7}$ led to the isolation of the known ACG molvizarin (1) by HPLC with an analytical Phenomenex ${ }^{\circledR}$ Luna $10 \mu$ Silica (2) column, with hexane:ethyl acetate:acetone (7:2:1) as solvent at flow rate of $1 \mathrm{~mL} / \mathrm{min}, \mathrm{t}_{\mathrm{R}} 40.6 \mathrm{~min}$. Purification and evaluation of the remaining fractions $\left(\mathrm{E}_{1.6 .5 .8}-\mathrm{E}_{1.6 .5 .10}\right)$ by $\mathrm{CC}$ on silica gel (with a gradient of hexane:ethyl acetate) and PLC (using as the organic phase a mixture of $\mathrm{CHCl}_{3}: \mathrm{MeOH}$ :acetone: $\mathrm{H}_{2} \mathrm{O}$ (13:7:1:3) as eluent) led to the isolation of cherimolin-1 (2), motrilin (3), annonacin (4) and annonisin (5).

ACGs 1-4 have been reported previously in seeds from the species studied here [30-32]. Nevertheless, all of the compounds are described for the first time in Annona cherimola Mill. deciduous leaves. Annonisin (5) has been isolated from Annona atemoya seeds [33] and it is reported for the first time in this species.

\subsection{Synthesis of SMPMs-ACGs}

A variation of the method of Mejías and co-workers [28] was used. $40 \mathrm{mg}$ of annonacin was dissolved in $4 \mathrm{~mL}$ of THF $(0.0168 \mathrm{mM}) .160 \mathrm{mg}$ of $\alpha-\mathrm{CD}(0.164 \mathrm{mmol})$ and $160 \mathrm{mg}$ of urea $(2.66 \mathrm{mmol})$ were weighed together and dissolved in $4 \mathrm{~mL}$ of water type I with sonication to enhance the dissolution process. Annonacin solution was added dropwise to the cyclodextrin solution and this mixture was stirred for $24 \mathrm{~h}$ at $40{ }^{\circ} \mathrm{C}$ followed by dialysis for $0.5 \mathrm{~h}$. A Spectra/Pore ${ }^{\circledR}$ membrane (Sigma Adrich, Steinheim, Germany) with 6000-8000 AMU cut off was loaded with the solution and the sample was lyophilized to obtain a fine powdery white solid. 


\subsection{Electron Microscopy}

The morphology and particle size of SMPMs-ACGs were studied using a JEOL2100 transmission electron microscope (JEOL, Tokyo, Japan). An LC300-Cu-150 grid with lacey carbon film was employed to prepare all the samples. Each electron microscopy sample was prepared by dispersing the solid in a miliQ quality degree water and dropping the solution onto a copper grid with lacey carbon. The copper grid with the sample was dried overnight to evaporate the solvent before microscopic analysis. The staining process was avoided to facilitate the correct elucidation of the micelle structures.

\subsection{Encapsulation Efficiency}

The percentage of annonacin inside the supramolecular polymer micelles was determined by breaking the shell to release the bioactive compound. The samples were dissolved in $\mathrm{CHCl}_{3}$ to remove this external layer of the core/shell systems and it was vortexed once. The organic solvent released the core compound and, subsequently, the absorbance of annonacin was measured by UV-Vis spectroscopy (Varian Cary 50 BIO spectrophotometer, Spijkenisse, The Netherlands). Absorbance values were converted to concentration values with a calibration curve (Figure S7).

\subsection{Compound Release}

A $1000 \mathrm{ppm}$ concentration of the encapsulated system was analyzed by UV-Vis spectroscopy (Varian Cary $50 \mathrm{BIO}$ spectrophotometer). Successive spectra were acquired at different time intervals and the variation in the absorbance bands for annonacin (4) was studied. Scans from 200 to $600 \mathrm{~nm}$ were recorded every $30 \mathrm{~s}$ for the first $10 \mathrm{~min}$, then a spectrum was acquired every minute up to $30 \mathrm{~min}$ and thereafter a spectrum every $15 \mathrm{~min}$ up to $24 \mathrm{~h}$. Each experiment was carried out at $36^{\circ} \mathrm{C}$ in saline buffer at $\mathrm{pH} 7.4$, in the absence of light and with stirring, to simulate the conditions of a living organism.

\subsection{Bioavailability Studies}

The bioavailability of 4 when encapsulated in SMPMs of $\alpha$-CD and urea was studied in a simulated gastrointestinal model based on the method described by Mejias et al. [28]. For the sake of comparison, this assay was also carried out on free annonacin. The concentration to calculate bioavailability was obtained from the calibration curve mentioned previously, with the absorbance values measured at $284.9 \mathrm{~nm}$. The bioavailability index was determined using the following expression [53]:

$$
\text { Bioavailability }(\%)=100 \times(\mathrm{Cm} / \mathrm{Ci})
$$

where $\mathrm{Cm}$ is the concentration of annonacin solubilized in the supernatant and $\mathrm{Ci}$ is the concentration of the initial amount added to the simulated digestive system.

\subsection{Cell Lines and Cell Cultures}

IGROV-1 (human ovarian carcinoma), HeLa (human cervix carcinoma), $\mathrm{CHO}$ (Chinese hamster ovary) and HEK-293 (human embryonic kidney 293) cells were cultured as monolayers in DMEM (GIBCO) supplemented with 10\% fetal bovine serum, $5 \%$ glutamine, $5 \%$ non-essential amino acids, $5 \%$ penicillin-streptomycin and 5\% sodium pyruvate. Cells were maintained in a HERA Cell 150i (Thermo Scientific) incubator at $37^{\circ} \mathrm{C}, 5 \% \mathrm{CO}_{2}$ and $95 \%$ humidity.

\subsection{Cell Viability Assay}

Tumoral cell lines (HeLa and IGROV-1) and non-tumoral cells (HEK-293) were used for the experiments. $1.5 \times 10^{5}$ cells per mL were seeded in 6-well plates (VWR, Langenfeld, Germany) in complete medium. Extracts and pure compounds at $100 \mathrm{ppm}$ and $100 \mu \mathrm{M}$, respectively, were dissolved in DMSO $(0.1 \% v / v)$ and added for $24 \mathrm{~h}$. Free annonacin in DMSO was also evaluated in the concentration range 6.25 to $100 \mu \mathrm{M}$ for $24 \mathrm{~h}$. Further studies with supramolecular polymer micelles of annonacin 
diluted in PBS at $100 \mu \mathrm{M}$ (170.5 ppm), as well as SMPMs empty at $170.5 \mathrm{ppm}$, were performed for $24 \mathrm{~h}$. SMPMs empty has been obtained following the same synthetic procedure for SMPMs-ACGs, but without adding annonacin. The amount required for the bioassay was calculated taking into account the encapsulation efficiency to afford the polymeric micelle (35\%) to a final concentration of $100 \mu \mathrm{M}$ of annonacin. Control cultures, including cells treated either with $0.1 \%$ DMSO or PBS $1 \mathrm{X}$, were also included in each experiment. Cell viability was evaluated by the Trypan blue assay. Trypan blue solution ( $0.4 \%$ Sigma Aldrich, Steinheim, Germany) was mixed 1:1 with a sample of control or treated cells. After incubation for $2 \mathrm{~min}$, a fraction of blue-stained cells was assessed using an Automated TC20 Cell Counter (Bio-Rad). IC 50 values were determined with GraphPad (Prism software v. 5.00). Experiments were carried out at least in triplicate and data are expressed as the mean \pm SD. All data were analyzed using one-way ANOVA and values were considered to be statistically significant when $p<0.05$.

\subsection{Fluorescence Microscopy}

HeLa cells were grown on $11 \times 22 \mathrm{~mm}$ coverslips (Thomas Scientific, Swedesboro, NJ, USA) and incubated for $20 \mathrm{~h}$. with annonacin at $100 \mu \mathrm{M}$ in culture medium as described above. Caspase-3 activity assay was performed according to the manufacturer's protocol [41,54]. Primary rabbit active caspase-3 antibody (1:500 dilution) and secondary fluorescein isothiocyanate (FITC)-conjugated goat anti-rabbit IgG antibody (dilution 1:100) were used for the incubation. The samples were observed using a Zeiss Axiophot microscope (Carl Zeiss, Oberkochen, West Germany) and images were taken with a Zeiss Axiocam 503 camera (Carl Zeiss, Jena, Germany).

Fluorescence intensity measurements, $n=3$, and multiple ROIs (regions of interest) were measured from groups of 20-30 cells. Images were transformed to 8-bit gray scale and fluorescence intensity was analyzed with ImageJ $1.53 \mathrm{e}$, using the particle analysis function. One-way ANOVA followed by a Tukey multiple comparisons test was performed to compare mean fluorescence intensity between the treatment groups using the GraphPad Prism version 5.0 (GraphPad Software, San Diego, CA, USA). Triplicate measurements were done in 3 randomly selected areas of each of the cell culture fields with a background correction. All data were expressed as the mean \pm SEM.

\section{Conclusions}

The present study shows the isolation of five ACGs that are described for the first time in A. cherimola deciduous leaves. One of the ACGs, annonisin (5), is reported for the first time in this species. In vitro cytotoxicity experiments showed strong toxicity against HeLa and IGROV-1 tumoral cell lines. Specially, annonacin (4) was found to be four- and two-times more potent in tumoral cells than in non-tumoral human embryonic kidney cells (HEK-293) at $50 \mu \mathrm{M}$. In view of these results, compound 4 was encapsulated in an effort to improve solubility and enable the development of nutraceutical or food supplements. SMPMs were successfully synthesized by employing $\alpha$-cyclodextrin and urea as building blocks, as evidenced by TEM images and NMR studies of cyclodextrin signals. The structure corresponded to a core/shell system with a wall thickness close to $8 \mathrm{~nm}$. According to molecular models developed with semi-empirical methods, between six and eight cyclodextrin units form the shell structure. Studies on the delivery of 4 at $37^{\circ} \mathrm{C}$ in PBS showed a release process that began after $17 \mathrm{~h}$ of being dissolved when it was encapsulated in the supramolecular polymer micelles. Furthermore, compound 4 remained stable in solution after being delivered. Kinetic analysis fitted with the Hixson-Crowell model is consistent with a release procedure by size reduction but with the geometrical form kept constant. Bioavailability studies showed an increase in stability and uptake capability of 4 when it was encapsulated in the SMPMs. These results highlight the use of supramolecular polymer micelles as nanocarriers for annonaceous acetogenins due to the improvements in the solubility, bioavailability and activity of annonacin. This by-product could be a starting point for the development of nutraceuticals with anticancer properties. These findings suggest that SMPMs of annonacin may 
become a promising candidate for clinical antitumor therapy and reduced side effects. Further in vivo experiments are needed.

\section{Patents}

The work reported in this manuscript has resulted in the filing of a patent whose identifier is: P201900173.

Supplementary Materials: The following are available online, Physical data. ${ }^{1} \mathrm{H}$ and ${ }^{13} \mathrm{C}$ spectra. Figure S1: Cell viability by dye exclusion against ovarian carcinoma cells (IGROV-1) for the first (A), second (B) and third (C) fractionations of A. cherimola deciduous leaves. Extracts were evaluated at $100 \mathrm{ppm}$ for $24 \mathrm{~h}$. Experiments were performed in triplicate and data are expressed as mean $\pm \mathrm{SD}, n=3$. Figure S2: $\mathrm{D}_{2} \mathrm{O}^{1} \mathrm{H}-\mathrm{NMR}$ comparison between $\alpha-C D, \alpha-C D /$ urea polyrotaxane, SMPMs-ACGs and SMPMs-ACGs with phenol, from bottom to top. Figure S3: ROESYAD 2D experiments. Figure S4: SMPMs wall thickness size distribution. Figure S5: SMPMs size distribution. Figure S6: PM3 model of the SMPM shell in the case of two units of $\alpha$-CD and thirty-two molecules of urea. (A) Biased geometry, with a distance of $26.46 \AA$ between cyclodextrin molecules. (B) Truncated cone geometry, with a distance of $17.47 \AA$ between cyclodextrin molecules (hydrogens are not represented). Figure S7: Calibration curve for annonacin in $\mathrm{CHCl}_{3}$.

Author Contributions: Conceptualization, M.T.G., A.G.D., F.J.R.M. and F.A.M.; methodology, validation, formal analysis, software, data curation and writing-original draft preparation, M.T.G., A.G.D. and F.J.R.M.; resources, D.M.; writing - review and editing, visualization, supervision, project administration, and funding acquisition, J.M.G.M., M.M.V. and F.A. Please turn to the CRediT taxonomy for the term explanation. Authorship must be limited to those who have contributed substantially to the work reported. All authors have read and agreed to the published version of the manuscript.

Funding: This work was financially supported by the 'Ministerio de Economía y Competitividad' (Project AGL2017-88083-R), Spain.

Acknowledgments: The authors thank the 'Área de Sistemas de Información' from University of Cadiz (Supercomputación) for computational facilities support and 'Centro Nacional de Investigaciones Oncológicas' (CNIO, Madrid) for supplying the cell lines. F.J.R.M thanks Universidad de Cádiz for predoctoral support under grant 2018-009/PU/EPIF-FPI-CT/CP.

Conflicts of Interest: The authors declare no conflict of interest.

\section{References}

1. Liaw, C.C.; Wu, T.Y.; Chang, F.-R.; Wu, Y.C. Historic perspectives on annonaceous acetogenins from the chemical bench to preclinical trials. Planta Med. 2010, 76, 1390-1404. [CrossRef] [PubMed]

2. Bermejo, A.; Figadère, B.; Zafra-Polo, M.C.; Barrachina, I.; Estornell, E.; Cortes, D. Acetogenins from Annonaceae: Recent progress in isolation, synthesis and mechanisms of action. Nat. Prod. Reports 2005, 22, 269-303. [CrossRef] [PubMed]

3. Zafra-Polo, M.; González, M.; Estornell, E.; Sahpaz, S.; Cortes, D.; Martínez, D.C. Acetogenins from annonaceae, inhibitors of mitochondrial complex I. Phytochemistry 1996, 42, 253-271. [CrossRef]

4. Smith, R.E.; Tran, K.; Richards, K.M. Bioactive annonaceous acetogenins. In Studies in Natural Products Chemistry; Atta-ur-Rahman, Ed.; Elsevier BV: Amsterdam, The Netherlands, 2014; Volume 41, pp. $95-117$. ISBN 9780444632944.

5. Oberlies, N.H.; Chang, A.C.J.; McLaughlin, J.L. Structure-activity relationships of diverse annonaceous acetogenins against multidrug resistant human mammary adenocarcinoma (MCF-7/Adr) Cells. J. Med. Chem. 1997, 40, 2102-2106. [CrossRef] [PubMed]

6. Miyoshi, H.; Ohshima, M.; Shimada, H.; Akagi, T.; Iwamura, H.; McLaughlin, J.L. Essential structural factors of annonaceous acetogenins as potent inhibitors of mitochondrial complex I. Biochim. Biophys. Acta 1998, 1365, 443-452. [CrossRef]

7. Díaz-De-Cerio, E.; Saez, L.M.A.; Gómez-Caravaca, A.M.; Verardo, V.; Fernández-Gutiérrez, A.; Fernández, I.; Arráez-Román, D. Characterization of bioactive compounds of Annona cherimola L. leaves using a combined approach based on HPLC-ESI-TOF-MS and NMR. Anal. Bioanal. Chem. 2018, 410, 3607-3619. [CrossRef]

8. Wele, A.; Landon, C.; Labbe, H.; Vovelle, F.; Zhang, Y.; Bodo, B. Sequence and solution structure of cherimolacyclopeptides A and B, novel cyclooctapeptides from the seeds of Annona cherimola. Tetrahedron 2004, 60, 405-414. [CrossRef] 
9. Jamkhande, P.G.; Ajgunde, B.R.; Jadge, D.R. Annona cherimola Mill. (Custard apple): A review on its plant profile, nutritional values, traditional claims and ethnomedicinal properties. Orient. Pharm. Exp. Med. 2017, 17, 189-201. [CrossRef]

10. Rodríguez-Sánchez, D.G.; Pacheco, A.; Villarreal-Lara, R.; Ramos-González, M.R.; Ramos-Parra, P.A.; Granados-Principal, S.; De La Garza, R.I.D.; Garcia-Rivas, G.; Brenes, C.H.; De La Garza, R.I.D. Chemical profile and safety assessment of a food-grade acetogenin-enriched antimicrobial extract from avocado seed. Molecules 2019, 24, 2354. [CrossRef]

11. González, E.M.; Fernández, A.E.L.; Sáyago-Ayerdi, S.G.; Estrada, R.M.V.; Vallejo, L.G.Z. In vitro antioxidant capacity of crude extracts and acetogenin fraction of soursop fruit pulp. Pharm. Anal. Acta 2017, 8, 1-7. [CrossRef]

12. Guillopé, R.; Escobar-Khondiker, M.; Guérineau, V.; Laprévote, O.; Höglinger, G.U.; Champy, P. Kaurenoic Acid from Pulp of Annona cherimolia in regard to Annonaceae-induced Parkinsonism. Phytothe. Res. 2011, 25, 1861-1864. [CrossRef] [PubMed]

13. Chih, H.-W.; Chiu, H.F.; Tang, K.S.; Chang, F.R.; Wu, Y.C. Bullatacin, a potent antitumor annonaceous acetogenin, inhibits proliferation of human hepatocarcinoma cell line 2.2.15 by apoptosis induction. Life Sci. 2001, 69, 1321-1331. [CrossRef]

14. Fang, X.P.; Rieser, M.J.; Gu, Z.M.; Zhao, G.X.; McLaughlin, J.L. Annonaceous acetogenins: An updated review. Phytochem. Anal. 1993, 4, 27-48. [CrossRef]

15. Oberlies, N.H.; Jones, J.L.; Corbett, T.H.; Fotopoulos, S.S.; McLaughlin, J.L. Tumor cell growth inhibition by several Annonaceous acetogenins in an in vitro disk diffusion assay. Cancer Lett. 1995, 96, 55-62. [CrossRef]

16. Colom, O.A.; Salvatore, A.; Willink, E.; Ordóñez, R.; Isla, M.I.; Neske, A.; Bardón, A. Insecticidal, mutagenic and genotoxic evaluation of annonaceous acetogenins. Nat. Prod. Commun. 2010, 5, 391-394. [CrossRef]

17. Cerella, C.; Radogna, F.; Dicato, M.; Diederich, M. Natural compounds as regulators of the cancer cell metabolism. Int. J. Cell Biol. 2013, 2013, 639401. [CrossRef]

18. Qayed, W.S.; Aboraia, A.S.; Abdel-Rahman, H.M.; Youssef, A.F. Annonaceous acetogenins as a new anticancer agent. Der Pharma Chem. 2015, 7, 24-35.

19. Yuan, F.; Bai, G.; Chen, Y.; Miao, Y.; Chen, J.; Li, X. Structure-activity relationships of diverse ACGs against multidrug resistant human lung cancer cell line A549/Taxol. Bioorg. Med. Chem. Lett. 2015, 25, 787-790. [CrossRef]

20. McLaughlin, J.L. Paw paw and cancer: Annonaceous acetogenins from discovery to commercial products. J. Nat. Prod. 2008, 71, 1311-1321. [CrossRef]

21. Chen, Y.; Chen, J.W.; Xu, S.S.; Wang, Y.; Li, X.; Cai, B.C.; Fan, N.B. Antitumor activity of annonaceous acetogenins in HepS and S180 xenografts bearing mice. Bioorg. Med. Chem. Lett. 2012, 22, 2717-2719. [CrossRef]

22. Chen, Y.; Chen, J.-W.; Zhai, J.-H.; Wang, Y.; Wang, S.L.; Li, X. Antitumor activity and toxicity relationship of annonaceous acetogenins. Food Chem. Toxicol. 2013, 58, 394-400. [CrossRef] [PubMed]

23. Alali, F.Q.; Liu, X.; McLaughlin, J.L. Annonaceous acetogenins: Recent progress. J. Nat. Prod. 1999, 62, 504-540. [CrossRef] [PubMed]

24. Ahammadsahib, K.; Hollingworth, R.; McGovren, J.; Hui, Y.H.; McLaughlin, J. Mode of action of bullatacin: A potent antitumor and pesticidal annonaceous acetogenin. Life Sci. 1993, 53, 1113-1120. [CrossRef]

25. Macías, F.A.; Mejías, F.J.R.; Molinillo, J.M.G. Recent advances in allelopathy for weed control: From knowledge to applications. Pest. Manag. Sci. 2019, 75, 2413-2436. [CrossRef]

26. Li, H.; Li, Y.; Ao, H.; Bi, D.; Han, M.; Guo, Y.; Wang, X. Folate-targeting annonaceous acetogenins nanosuspensions: Significantly enhanced antitumor efficacy in HeLa tumor-bearing mice. Drug Deliv. 2018, 25, 880-887. [CrossRef]

27. Lee, W.H.; Bebawy, M.; Loo, C.Y.; Luk, F.; Mason, R.S.; Rohanizadeh, R. Fabrication of curcumin micellar nanoparticles with enhanced anti-cancer activity. J. Biomed. Nanotechnol. 2015, 11, 1093-1105. [CrossRef]

28. Mejías, F.J.R.; Gutiérrez, M.T.; Durán, A.G.; Molinillo, J.M.G.; Valdivia, M.M.; Macías, F.A. Provitamin supramolecular polymer micelle with $\mathrm{pH}$ responsiveness to control release, bioavailability enhancement and potentiation of cytotoxic efficacy. Colloids Surf. B 2019, 173, 85-93. [CrossRef]

29. Gutiérrez, M.T.; Mejías, F.J.R.; Durán, A.G.; Molinillo, J.M.G.; Valdivia, M.M.; Macías, F.A. Procedimiento de Obtención de una Composición Farmacéutica Empleando Acetogeninas con Micelas Poliméricas Supramoleculares Para el Tratamiento de Cáncer de Piel; University of Cadiz: Cádiz, Spain, 2019; p. 201900173. 
30. Cortes, D.; Myint, S.H.; Dupont, B.; Davoust, D.; Martínez, D.C. Bioactive acetogenins from seeds of Annona cherimolia. Phytochemistry 1993, 32, 1475-1482. [CrossRef]

31. Cortes, D.; Myint, S.H.; Hocquemiller, R.; Martínez, D.C. Molvizarin and motrilin: Two novel cytotoxic bis-tetrahydro-furanic $\gamma$-lactone acetogenins from Annona cherimolia. Tetrahedron 1991, 47, 8195-8202. [CrossRef]

32. Kim, D.H.; Son, J.K.; Woo, M.H. Annomocherin, annonacin and annomontacin: A novel and two known bioactive mono-tetrahydrofuran annonaceous acetogenins from Annona cherimolia seeds. Arch. Pharm. Res. 2001, 24, 300-306. [CrossRef]

33. Duret, P.; Hocquemiller, R.; Cavé, A. Annonisin, a bis-tetrahydrofuran acetogenin from Annona atemoya seeds. Phytochemistry 1997, 45, 1423-1426. [CrossRef]

34. Son, J.K.; Kim, D.H.; Woo, M.H. Two new epimeric pairs of acetogenins bearing a carbonyl group from Annona cherimolia seeds. J. Nat. Prod. 2003, 66, 1369-1372. [CrossRef] [PubMed]

35. Sun, S.; Liu, J.; Zhou, N.; Zhu, W.; Dou, Q.P.; Zhou, K. Isolation of three new annonaceous acetogenins from Graviola fruit (Annona muricata) and their anti-proliferation on human prostate cancer cell PC-3. Bioorg. Med. Chem. Lett. 2016, 26, 4382-4385. [CrossRef] [PubMed]

36. Zeng, L.; Wu, F.E.; Oberlies, N.H.; McLaughlin, J.L.; Sastrodihadjo, S. Five new monotetrahydrofuran ring acetogenins from the leaves of Annona muricata. J. Nat. Prod. 1996, 59, 1035-1042. [CrossRef]

37. Chen, Y.; Qiu, Y.; Miao, Y.J.; Yuan, F.; Chen, J.W.; Li, X. SARs of ACGs against diverse human tumor cells. Med. Chem. Res. 2015, 24, 3212-3217. [CrossRef]

38. Bézivin, C.; Tomasi, S.; Dévéhat, F.L.L.; Boustie, J. Cytotoxic activity of some lichen extracts on murine and human cancer cell lines. Phytomedicine 2003, 10, 499-503. [CrossRef]

39. Elmore, S.A. Apoptosis: A review of programmed cell death. Toxicol. Pathol. 2007, 35, 495-516. [CrossRef]

40. Yuan, S.S.F.; Chang, H.L.; Chen, H.; Yeh, Y.T.; Kao, Y.H.; Lin, K.-H.; Wu, Y.C.; Su, J.H. Annonacin, a mono-tetrahydrofuran acetogenin, arrests cancer cells at the G1 phase and causes cytotoxicity in a Bax- and caspase-3-related pathway. Life Sci. 2003, 72, 2853-2861. [CrossRef]

41. Yiallouris, A.; Patrikios, I.S.; Johnson, E.O.; Sereti, E.; Dimas, K.; De Ford, C.; Fedosova, N.U.; Graier, W.F.; Sokratous, K.; Kyriakou, K.; et al. Annonacin promotes selective cancer cell death via NKA-dependent and SERCA-dependent pathways. Cell Death Dis. 2018, 9, 764. [CrossRef]

42. Pastor, A.; Martínez-Viviente, E. NMR spectroscopy in coordination supramolecular chemistry: A unique and powerful methodology. Coord. Chem. Rev. 2008, 252, 2314-2345. [CrossRef]

43. Šmejkalová, D.; Piccolo, A. Aggregation and disaggregation of humic supramolecular assemblies by NMR diffusion ordered spectroscopy (DOSY-NMR). Environ. Sci. Technol. 2008, 42, 699-706. [CrossRef]

44. Li, F.; Chen, B.; Ping, Z.; Jia, X.; Guo, X.; Xiao, L.; Liu, L. Synthesis of 6-O-Poly(€-caprolactone)-L-ascorbic acid and its controlled release from supramolecular polymer micelles. Macromol. Biosci. 2014, 14, 280-288. [CrossRef]

45. Shi, Y.; Luo, H.Q.; Li, N.B. Determination of the critical premicelle concentration, first critical micelle concentration and second critical micelle concentration of surfactants by resonance Rayleigh scattering method without any probe. Spectrochim. Acta Part. A Mol. Biomol. Spectrosc. 2011, 78, 1403-1407. [CrossRef]

46. Li, Y.; Chen, Y.; Dong, H.; Dong, C. Supramolecular, prodrug-based micelles with enzyme-regulated release behavior for controlled drug delivery. MedChem Comm 2015, 6, 1874-1881. [CrossRef]

47. Cabral, H.; Miyata, K.; Osada, K.; Kataoka, K. Block copolymer micelles in nanomedicine applications. Chem. Rev. 2018, 118, 6844-6892. [CrossRef]

48. Dong, H.; Li, Y.; Cai, S.; Zhuo, R.; Zhang, X.-Z.; Liu, L. A Facile one-pot construction of supramolecular polymer micelles from $\alpha$-cyclodextrin and poly( $\varepsilon$-caprolactone). Angew. Chem. Int. Ed. 2008, 47, 5573-5576. [CrossRef]

49. Dash, S.; Murthy, P.; Nath, L.; Chowdhury, P. Kinetic modeling on drug release from controlled drug delivery systems. Acta Pol. Pharm. Drug Res. 2010, 67, 217-223. [CrossRef]

50. Sidorov, I.A.; Blumenthal, R.; Dimitrov, D.S. A model of drug delivery to normal and cancer cells by antibody-targeted nanoliposomes. J. Comput. Theor. Nanosci. 2006, 3, 405-411. [CrossRef]

51. Chen, S.; Zhu, J.; Cheng, J. Preparation and in vitro evaluation of a novel combined multiparticulate delayed-onset sustained-release formulation of diltiazem hydrochloride. Pharmazie 2007, 62, 907-913. [CrossRef] [PubMed] 
52. Bruschi, M.L. Mathematical models of drug release. In Strategies to Modify the Drug Release from Pharmaceutical Systems; Bruschi, M.L., Ed.; Elsevier Ltd.: Amsterdam, The Netherlands, 2015; pp. 63-86. ISBN 9780081000922.

53. Aditya, N.; Aditya, S.; Yang, H.J.; Kim, H.W.; Park, S.O.; Ko, S.H. Co-delivery of hydrophobic curcumin and hydrophilic catechin by a water-in-oil-in-water double emulsion. Food Chem. 2015, 173, 7-13. [CrossRef] [PubMed]

54. Zhao, H.W.; Zhou, N.; Jin, F.; Wang, R.; Zhao, J.Q. Metformin reduces pancreatic cancer cell proliferation and increases apoptosis through MTOR signaling pathway and its dose-effect relationship. Eur. Rev. Med. Pharmacol. Sci. 2020, 24, 5336-5344. [PubMed]

Sample Availability: Samples of the acetogenins molvizarin (1) and annonacin (4) as well as SMPMs of annonacin are available from the authors.

Publisher's Note: MDPI stays neutral with regard to jurisdictional claims in published maps and institutional affiliations.

(C) 2020 by the authors. Licensee MDPI, Basel, Switzerland. This article is an open access article distributed under the terms and conditions of the Creative Commons Attribution (CC BY) license (http://creativecommons.org/licenses/by/4.0/). 